\title{
Harmonisation of Pharmaceutical Take-Back Systems in the EU
}

\author{
Kateřina Mitkidis | ORCID: 0000-0002-2775-0843 \\ Department of Law, Aarhus University, Aarhus, Denmark \\ Corresponding author \\ katpe@law.au.dk \\ Viktoria Obolevich | ORCID: 0000-0003-1970-3606 \\ Department of Law, Aarhus University, Aarhus, Denmark \\ vao@law.au.dk
}

Polymeros Chrysochou | ORCID: 0000-0002-7905-5658

Department of Management, Aarhus University, Aarhus, Denmark polyc@mgmt.au.dk

\author{
Panagiotis Mitkidis | ORCID: 0000-0002-9495-7369 \\ Department of Management, Aarhus University, Aarhus, Denmark \\ Center for Advanced Hindsight, Duke University, Durham, NC, USA \\ pm@mgmt.au.dk
}

\begin{abstract}
When medicines enter the environment, they harm living species and ecosystems. Improper disposal of household pharmaceutical waste increases the concentration of pharmaceuticals in the environment and thus their detrimental impacts. Since 2004, the EU has obliged its Member States to establish 'an appropriate collection system' for unused and/or expired medication. However, as no implementation guidelines exist, large differences in the systems and their use remain. Pressure for adoption of guidelines harmonising the systems across the EU has been increasing. We address the question whether such harmonisation could mitigate pharmaceutical pollution, and which regulatory measures would be appropriate. To answer this, we conduct a comparative investigation of the systems' regulation and an empirical study of citizens' beliefs and behaviour across four European countries. We find a potential for increasing the effectiveness of pharmaceutical take-back systems through their harmonisation and conclude that the EU has the competence and tools to regulate this.

(C) KATEŘINA MITKIDIS ET AL., 2021 | DOI:10.1163/15718093-BJA10051

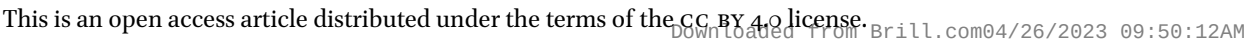




\section{Keywords}

pharmaceutical law - pharmaceuticals in the environment $(\mathrm{PiE})$ - pharmaceutical take-back systems - comparative legal analysis - harmonisation

\section{Intro to the PiE Problem, Pharmaceutical Waste, and Take-Back Systems}

When pharmaceuticals ${ }^{1}$ that are designed to treat humans enter the natural environment, they may irreversibly harm living species and ecosystems. ${ }^{2}$ While the extent of such harm remains veiled with uncertainties, ${ }^{3}$ there is a growing evidence of pharmaceuticals' presence in the environment globally. ${ }^{4}$ Recent research shows that human exposure to individual pharmaceuticals through the environment surpasses the predicted no-effect levels, ${ }^{5}$ casting doubts on the prevailing understanding so far, namely that the risks of pharmaceuticals in the environment $(\mathrm{PiE})$ to human health are only negligible. ${ }^{6}$ Concerns raised by this research are only mounting when combined with the knowledge about the current status of global anti-microbial resistance (AMR ${ }^{7}$ and the current lack of knowledge about the 'cocktail' effects of pharmaceuticals and other chemicals through the environment on human health. ${ }^{8}$

1 The terms 'pharmaceuticals', 'medicinal products' and 'medicines' are used interchangeably in this paper.

2 O. Enick and M. Moore, 'Assessing the assessments: Pharmaceuticals in the environment', Environmental Impact Assessment Review 27(8) (2007) 707-729, at 715, https://doi .org/10.1016/j.eiar.2007.01.001.

3 B.M. Peake, R. Braund, A.Y.C. Tong and L.A. Tremblay, The Life-Cycle of Pharmaceuticals in the Environment, (Amsterdam: Elsevier/Woodhead Publishing, 2016) p. 109.

4 T. aus der Beek, F.-A. Weber, A. Bergmann, S. Hickmann, I. Ebert, A. Hein and A. Küster, 'Pharmaceuticals in the environment - Global occurrences and perspectives', Environmental Toxicology Chemistry 35(4) (2016) 823-835, DOI:10.1002/etc.3339.

5 Ibid.

6 See, e.g., F.M. Christensen, 'Pharmaceuticals in the Environment - A Human Risk?', Regulatory Toxicology and Pharmacology 28(3) (1998) 212-221, DOI:10.1006/rtph.1998.1253.

7 World Health Organization (wHO), Antimicrobial resistance, available online at https://www .who.int/health-topics/antimicrobial-resistance (accessed 9 October 2020).

8 See, e.g., WHO, 'Pharmaceuticals in Drinking-water', wHO/HSE/WSH/11.o5, 2011, p. 28; K.E. Arnold, A.B.A. Boxall, A.R. Brown, R.J. Cuthbert, S. Gaw, T.H. Hutchinson, S. Jobling, J.C. Madden, C.D. Metcalfe, V. Naidoo, R.F. Shore, J.E. Smits, M.A. Taggart and H.M. Thompson, 'Assessing the exposure risk and impacts of pharmaceuticals in the environment on individuals and ecosystems' Biology Letters 9(4) (2013) 20130492, DOI:10.1098/rsbl.2013.0492, p. 3. 
Pharmaceuticals enter into the natural environment at three stages of their life-cycle: manufacturing, consumption, and end-of-life waste management. While consumption is responsible for the largest amount of PiE, ${ }^{9}$ it is the production processes that lead to the release of active pharmaceutical ingredients into the environment at the highest concentrations..$^{10}$ End-of-life pharmaceutical waste management had long been at the outskirts of the PiE discussion, but its momentum has been growing as any regulatory efforts of the production and use stages remain very difficult to implement. Regulation of the production of pharmaceuticals assumes extraterritorial legal effects, ${ }^{11}$ while the consumption of pharmaceuticals is only expected to increase due to the expanded access to medicines, the aging of the global population, and the Covid-19 pandemic. ${ }^{12}$ Lowering the amounts of pharmaceutical waste and ensuring its responsible disposal have been identified as important steps in mitigating the PiE issue, ${ }^{13}$ and a step that can be taken immediately based on current regulation, thus not imposing large additional costs on the regulators or market participants. ${ }^{14}$

9 BIO Intelligence Service (BIO IS), Study on the environmental risks of medicinal products (Final Report prepared for Executive Agency for Health and Consumers 2013) (12 December 2013), available online at https://ec.europa.eu/health/sites/health/files/ files/environment/study_environment.pdf (accessed 7 June 2021), 'Between 30 and $9 \circ \%$ of the orally administered dose is generally excreted as active substance in the urine of animals and humans', p. 19.

10 D.G.J. Larsson, 'Pollution from drug manufacturing: review and perspectives', Philosophical transactions of the Royal Society of London, Series B, Biological Sciences 369(1656) (2014) 4, DOI:10.1098/rstb.2013.0571.

11 Extraterritorial legal effects in practice means that laws adopted in one jurisdiction influence behaviour of subjects and its perception as legal/illegal in another jurisdiction. Laws with exterritorial effects can be questioned in respect to their legitimacy.

12 K. Mitkidis, S.E. Walter and V. Obolevich, 'Towards Responsible Management of Pharmaceutical Waste in the EU' in: H.T. Anker and B.E. Olsen (eds.), Sustainable Management of Natural Resources: Legal Instruments and Approaches (Cambridge: Intersentia, 2018) pp. 63-8o.

13 European Commission, 'Communication from the Commission to the European Parliament, the Council and the European Economic and Social Committee, European Union Strategic Approach to Pharmaceuticals in the Environment', сом/2019/128 final, 11 March 2019.

14 K. Mitkidis and P. Mitkidis, "Homemade": The Vicious Circle of Household Pharmaceutical Waste', European Journal of Risk Regulation, 11(3) (2020) 693-697, DoI:10.1017/ err.2020.57. 


\subsection{Household Pharmaceutical Waste in Numbers}

The term 'end-of-life pharmaceutical waste' comprises unused and expired medication that is or should be discarded. It neither covers human excretion (and thus wastewater) nor industrial effluents. End-of-life pharmaceutical waste is discarded both at professional organizations, such as hospitals or elderly homes, and at households. The former is easier to regulate, as it involves healthcare professionals and specific locations. Thus, it is the household pharmaceutical waste that brings wrinkles to regulators' foreheads. Household pharmaceutical waste can be defined as consumer medication leftovers, i.e., unused and/or expired pharmaceuticals accumulated in households. ${ }^{15}$

Unused and expired pharmaceuticals represent wastage not only of finances, but also as a resource (medicine) that could be used by other patients in need. For example, the value of household pharmaceutical waste in England alone is estimated to amount to $£ 200$ million per year. ${ }^{16}$ The share of sold pharmaceuticals in the European Union (EU) that stays unused varies a lot among Member States. This share was estimated to range between $5 \%$ in Sweden and $50 \%$ in France. ${ }^{17}$

In the wake of the mounting evidence of the presence of pharmaceuticals in the environment and their detrimental impacts on living species, ${ }^{18}$ the EU already in 2004 introduced Article $127 \mathrm{~b}$ into directive 2001/83 establishing the Community code relating to medicinal products for human use (Community code). ${ }^{19}$ The Article prescribes that 'Member States shall ensure that appropriate collection systems are in place for medicinal products that are unused or have expired.' However, more implementation guidance is still missing; thus, leading to a variety of pharmaceutical take-back systems among EU Member States. While the majority of Member States have chosen pharmacies as

15 C.G. Daughton, Drugs and the Environment: Stewardship \& Sustainability, U.S. Environmental Protection Agency, EPA/6oo/R-10/106, 12 September 2010.

16 YHEc/School of Pharmacy, University of London, Evaluation of the Scale, Causes and Costs of Waste Medicines - Final Report, November 2010, p. 5.

17 BIO Is, supra note 9, p. 41.

18 See, e.g., D.G.J. Larsson, M. Adolfsson-Erici, J. Parkkonen, M. Pettersson, A.H. Berg, P.-E. Olsson and L. Förlina, 'Ethinyloestradiol - an undesired fish contraceptive?', Aquatic Toxicology 45(2) (1999) 91-97, DoI:10.1016/So166-445X(98)oo112-X; R.E. Green, I. Newton, S. Shultz, A.A. Cunningham, M. Gilbert, D.J. Pain and V. Prakash, 'Diclofenac poisoning as a cause of vulture population declines across the Indian subcontinent', Journal of Applied Ecology 41(5) (2004) 793-800, DOI:10.1111/j.0021-8901.2004.00954.X.

19 Directive 2001/83/EC of the European Parliament and of the Council of 6 November 2001 on the Community code relating to medicinal products for human use [2001] oJ L 311 as amended by Directive 2004/27/EC, OJ L 136 . 
collection points, ${ }^{20}$ other aspects such as financing of the take-back systems ${ }^{21}$ and the form of the actual hand-over of pharmaceutical waste differ. ${ }^{22}$

As the features of EU Member States' pharmaceutical take-back systems differ, so does the level of their use by citizens. A recent global literature review finds that while the majority of citizens in Sweden, Germany, and the Netherlands return their unused medicine to pharmacies, much fewer citizens in other European countries, e.g., Cyprus and Poland, do so. ${ }^{23}$ An alarming $95 \%$ of citizens in Romania dispose of unused medication via the garbage bin. ${ }^{24}$

\section{$1.2 \quad$ The Purpose and Structure of the Article}

On the provided background, the question arises whether the PiE problem in the EU could be mitigated by the harmonisation of the take-back systems' design across Member States, and which regulatory measures are appropriate to take in this respect.

We propose an answer to the above by conducting a comparative investigation of the regulation of pharmaceutical take-back systems and an empirical study of citizens' beliefs and behaviour across four European countries: Czechia, Denmark, Greece, and the UK. The rationale behind the choice of these countries was to represent different parts of the EU in respect to geographical location, economic development, ${ }^{25}$ and medicine consumption. ${ }^{26}$ While the UK has since exited the EU, ${ }^{27}$ there are still valuable lessons to

20 An overview is available at MEDSdisposal, http://medsdisposal.eu (accessed 14 October 2020); see also G. Vollmer, 'Disposal of Pharmaceutical Waste in Households - A European Survey', in K. Kümmerer and M. Hempel (eds.), Green and Sustainable Pharmacy (Heidelberg: Springer, 2010) p. 173, DoI:10.1007/978-3-642-05199-9_11.

21 An overview of industry financed pharmaceutical take-back systems can be found at: California Product Stewardship Council, https://www.calpsc.org/products/pharmaceuti cals/international-epr-programs-for-pharmaceuticals (accessed 14 October 2020).

In some Member States citizens are asked to return unused medicine in a plastic bag provided by the pharmacy (e.g., Greece), in others special containers are placed in pharmacies, where unused medicine can be dropped off (e.g., Spain).

23 F. Alnahas, P. Yeboah, L. Fliedel, A.Y. Abdin, and K. Alhareth, 'Expired Medication: Societal, Regulatory and Ethical Aspects of a Wasted Opportunity', International Journal of Environmental Research and Public Health 17(3) (2020) 787, DoI:10.339o/ijerph17030787.

24 D.M. Tit, S. Bungau, C. Nistor Cseppento, D.M. Copolovici and C. Buhas, 'Disposal of Unused Medicines Resulting from Home Treatment in Romania',Journal of Environmental Protection and Ecology 17(4) (2016) 1425-1433, at 1429.

25 GDP statistics (reference year 2019), available online at https://data.worldbank.org/ indicator/NY.GDP.MKTP.CD?locations=EU\&view=map (accessed 9 May 2021).

$26 \mathrm{OECD} / \mathrm{EU}$, Health at a Glance: Europe 2018: State of Health in the EU Cycle (Paris: OECD Publishing, 2018),Chapter 5, DOI: https://doi.org/10.1787/health_glance_eur-2018-en.

27 The study was designed in 2019 . 
learn from the UK's experience about the functioning of the pharmaceutical take-back systems, as the UK legislation in this area implements the applicable EU rules.

We organise the paper as follows. In section 2 we discuss the laws governing pharmaceutical take-back systems in the selected countries. In section 3 we provide a review of calls for the harmonisation of pharmaceutical take-back systems at EU level, relying on the discussion in relevant academic literature and reports prepared by or on behalf of public authorities. In section 4 we present the design and results of our empirical study. In section 5 , based on our theoretical analysis and the empirical data, we provide answers to a number of relevant questions, while in section 6 we conclude by providing recommendations for theory and public policy.

\section{Current Regulation and Practice of Take-Back Systems}

Improper disposal of household pharmaceutical waste through sink, toilet, garbage bins, or their burning at unauthorised places increases the concentration levels of active pharmaceutical ingredients in the environment and thus their detrimental impact on human and environmental health. As a response to the threat, the EU has introduced via amending Directive 2004/27/EC Article $127 \mathrm{~b}$ to the Community code requiring Member States to establish 'an appropriate collection system' for unused and/or expired medication. The underlying idea is that citizens hand over their household pharmaceutical waste to authorised entities, which have the necessary knowledge and resources to take care of the disposal in a responsible and environmentally sound manner. When such takeback systems are well-functioning, they reduce the environmental pollution levels and thus the negative impacts on environmental and human health, ${ }^{28}$ as well as they create positive spill-over effects concerning public safety (e.g., limiting the possibility of accidental drug poisoning) and increased public awareness of the PiE issue. ${ }^{29}$ Moreover, it is one of the simplest ${ }^{30}$ and inexpensive tools (in comparison to alternative and parallel solutions, such as the development and implementation of new waste-water treatment technologies) $)^{31}$

\footnotetext{
$28 \quad$ BIO Is, supra note 9, section 9.1.2.

29 Knowledge and Need Assessment on Pharmaceutical Products in Environmental Waters (KNAPPE) final report, 2008, p. 20.

3O $\quad$ BIO IS, supra note 9 , section 9.1.2.

31 KNAPPE final report, supra note 29, p. 20.
} 
for combatting PiE, and a tool that has the potential of gathering broad support across various stakeholders. ${ }^{32}$

Even without any further guidance from the EU, in most Member States household pharmaceutical waste is collected at pharmacies..$^{33}$ Returned pharmaceutical waste should in most cases find its way to incineration plants, which is considered to be the safest disposal route for most pharmaceuticals. ${ }^{34}$

While all EU Member States communicated transposition of Directive 2004/27/EC to the European Commission, ${ }^{35}$ information specifically on the obligation to establish a pharmaceutical collection system is missing in some. ${ }^{36}$ Moreover, the 'appropriateness' of the established take back systems can in some cases be questioned, as citizens across Europe use them at largely different levels. ${ }^{37}$ Although the reasons for not returning household pharmaceutical waste to the collection places vary among countries, some of the same reasons are found in most of them. These include lack of awareness of the collection systems, perceived inconvenience, and variance in patients' compliance with the prescribed therapy. ${ }^{38} \mathrm{~A}$ large EU survey from 2013 found that in average about $50 \%$ of household pharmaceutical waste was wrongly disposed of. ${ }^{39}$

Yet, it is not just the citizens' behaviour that has an impact on the use of pharmaceutical collection systems. The individuals receiving the waste from the citizens also play an important role. Yet, their attitudes in this respect have not been scrutinised so often. ${ }^{40}$ A study from Romania shows that the role of

32 Mitkidis and Mitkidis, supra note 14.

33 See: MEDSdisposal, available online at http://medsdisposal.eu (accessed 5 May 2021); Vollmer, supra note 20, p. 173.

34 E.M.N. Imad, A.E. Asim, J.M.S. Tasneem, S, Mahjoub, M.A.M. Wadha and S.B. Akshaya, 'Management of Post-Consumer Pharmaceutical Waste: An Overview', SOJ Pharmacy \& Pharmaceutical Sciences 4(5) (2017) 4, DOI: http://dx.doi.org/10.15226/2374-6866/ 4/5/oo171; European Commission, Commission Notice, Separate Collection of Household Hazardous Waste (6 November 2020), 2020/C 375/o1.

35 National transposition measures communicated by the Member States available online at https://eur-lex.europa.eu/legal-content/EN/NIM/?uri=CELEX:32004Loo27\&qid=16188 $35^{259145}$ (accessed 7 June 2021).

36 MEDSdisposal, http://medsdisposal.eu, retrieved 7 June 2021; e.g., Bulgaria.

37 See above, supra note 23 and supra note 24.

38 M.J. Amaral and L. Fop (нсwн), Unused Pharmaceuticals Where Do They End Up? A Snapshot of European Collection Schemes (December 2013), p. 1-32.

39 BIO Is, supra note 9, p. 18.

40 J.A. Singleton, L.M. Nissen, N. Barter and M. McIntosh, 'The global public health issue of pharmaceutical waste: what role for pharmacists?', Journal of Global Responsibility 5(1) (2014) 126-137, DoI:10.1108/JGR-o3-2014-ooog; from India: S. Aditya and A. Rattan, 'Minimizing Pharmaceutical Waste: The Role of the Pharmacist', Journal of Young Pharmacists 6(3) (2014) 14-19, DOI:10.5530/jyp.2014.3.3. 
pharmacists is central, stating that '[o]f the surveyed pharmacists, $16 \%$ work in pharmacies that do not collect unused/expired drugs from the population, and nearly $33 \%$ of those investigated have refused, at least once, to take the unused medicines from the people. ${ }^{41} \mathrm{~A}$ situation in which a citizen brings her household pharmaceutical waste into a pharmacy, and the pharmacist refuses to receive it, strongly discourages the citizen to do it again. Therefore, it is essential that the persons receiving pharmaceutical waste from citizens are fully informed about how to deal with it. Clear regulation is a precondition for such awareness both on the citizens' and pharmacists' side. One way to ensure a clear regulation within the EU would be through its harmonisation, or even unification.

\subsection{The EU Legal Framework}

The topic of pharmaceutical waste lies on the borderline between environmental law (waste law specifically) and health law. While the primary purpose of the pharmaceutical sector is to deliver medicinal products for the treatment of citizens, the majority of legislative acts in this area were adopted based on the internal market legal basis, ${ }^{42}$ rather than the protection of public health provisions in the EU treaties, ${ }^{43}$ not to mention the environmental provision. ${ }^{44}$ The main goal of European pharmaceutical law thus is the establishment of the common market in medicinal products, facilitating their unhindered movement within the borders of the EU, while ensuring their quality and safety. ${ }^{45}$ Securing public health comes in as a secondary, but at the same time a "decisive" 46 aim, through the integration principle included in Articles 9 and 168(1) TFEU, the latter stating that: 'A high level of human health protection shall be ensured in the definition and implementation of all Union policies and activities. ${ }^{\prime 7} \mathrm{~A}$ high level of both health and environmental protection is then required by Article 114(3) TFEU, where the Commission is instructed particularly to take into account 'any new development based on scientific facts'. Environmental protection is also to be considered within European pharmaceutical law based on the integration principle of Article 11 TFEU:

S. Bungau, D.M. Tit, K. Fodor, G. Cioca, M. Agop, C. Iovan, D.C. Nistor Cseppento, A. Bumbu and C. Bustea, 'Aspects Regarding the Pharmaceutical Waste Management in Romania', Sustainability 10(8) (2018) 2788, DOI: 10.339o/su10o82788. TFEU, Article 168 (ex. Article 152).

44 TFEU, Article 192 (ex. Article 175).

45 European Commission, 'Pharmaceutical Strategy for Europe', 2020, Сом(2020) 761 final.

46 Case C-547/14, Philip Morris Brands SARL [2016], ECLI:EU:C:2016:325, para. 6 o.

47 Emphasis added. 
'Environmental protection requirements must be integrated into the definition and implementation of the Union policies and activities, in particular with a view to promoting sustainable development.'48 However, the mandate of environmental protection may be interpreted as being weaker than that of the protection of public health. The 'integration' of environmental protection can be interpreted as a requirement to take some direct positive steps, for example, by mandating to conduct an environmental impact assessment. ${ }^{49}$ Protection of public health shall be 'ensured', which could be understood as leaving less space for error and, therefore, requiring stricter regulation.

\subsection{The Implementation of Article $127 b$ of the Community Code in National Law}

In the next, we turn to review the regulation of pharmaceutical waste collection systems in the four selected countries: Czechia, Denmark, Greece and the UK.

\subsubsection{Czechia}

Section 88(1) of the Act on Pharmaceuticals ${ }^{50}$ stipulates that expired or unused pharmaceuticals 'must be disposed of ... in a manner preventing any jeopardy to the life and health of people or animals or the environment.' Section 89(2) of the Act on Pharmaceuticals then obliges pharmacies to accept expired or unused pharmaceuticals from natural persons. After receiving pharmaceutical waste from natural persons, pharmacies must handle it according to the procedures applicable to hazardous waste ${ }^{51}$ within the context of the Wastes Act. ${ }^{52}$ The new Wastes Act of 2020 moreover introduced Part 11 (under Title VI) stipulating further pharmacies' obligations in this respect. Under section 91 of the Wastes Act, pharmacies must store received household pharmaceutical waste separately from waste they alone produce and keep a separate continuous record of it. Pharmacies do not dispose of the collected household pharmaceutical waste themselves, but hand it over to persons authorised to do so ('liquidators'). ${ }^{53}$ Liquidators shall take over the collected household pharmaceuticals from

\footnotetext{
48 Emphasis added.

49 J. Nowag, Environmental Integration in Competition and Free-Movement Laws, (Oxford: Oxford University Press, 2017), pp. 4-8.

50 Act no. $378 / 2007$ Coll. on Pharmaceuticals and on Amendments to Some Related Acts (the Act on Pharmaceuticals).

$5^{1} \quad$ Act on Pharmaceuticals, Section 88(2).

$5^{2}$ Act no. 541/2020 Coll. Act on Wastes (with effectiveness from 1.1.2021 replacing Act no. 185/2001 on Wastes and on Amendments to Some Related Acts) (Wastes Act).

53 Act on Pharmaceuticals, Section 88(3).
} 
pharmacies without charging them any fee; instead, they can then apply to the regional authorities for compensation of their incurred costs. ${ }^{54}$ Pharmacies do not have the possibility to apply for such a compensation. This possibility was removed from the Act on Pharmaceuticals as of 1 December 2019. Before this amendment, pharmacies were acting in a position of a middleman between the State and liquidators in the sense that pharmacies paid the service of liquidators (transport and disposal of the waste) and then alone applied to the regional authorities for compensation. As of 1 December 2019, pharmacies are not anymore in this middleman position; they can neither be charged by a liquidator nor apply for any compensation. Instead, the state compensates the liquidator directly.

According to the research conducted by the Czech State Institute for Drug Control (SUKL), Czech citizens returned to pharmacies medicines in the value of approx. EUR 128 million in 2018. That was four times more than in $2008 .{ }^{55}$ This would suggest an increase in the use of pharmaceutical take-back systems in Czechia. Yet, the use is far from optimal. su KL also states that about one fourth of the citizens still dispose of pharmaceuticals improperly through toilets or garbage bins. ${ }^{56}$ Such improperly disposed of household pharmaceutical waste amounted to the value of approx. EUR 5 O million in $2018 .{ }^{57}$ Other citizens simply store unused medicines at home.

\subsubsection{Denmark}

As with Czech pharmacies, Danish pharmacies are under a legal obligation to receive household pharmaceutical waste. ${ }^{58}$ This is done free of charge, meaning that neither the consumers returning pharmaceutical waste can be charged by the pharmacy, nor the pharmacy can be charged by the municipality for handling hazardous waste. ${ }^{59}$ Pharmacies enter into contracts with municipalities, who have the regulatory competence in the area of waste management, to make arrangements for the collection of household pharmaceutical

\footnotetext{
54 Act on Pharmaceuticals, Section 89(2).

55 SUKL, Průzkum SÚKL: Množství nevyužitých léčiv roste, v domácnostech je zbytečně hromadime (11 August 2020), available online at https://www.sukl.cz/sukl/pruzkum-sukl -mnozstvi-nevyuzitych-leciv-roste-v-domacnostech (accessed 7 June 2021).

$5^{6} \quad$ This number differs substantially from our empirical results, see Table 1.

57 Supra note 55 .

58 Lovbekendtgørelse 2018-06-12 nr. 801 om apoteksvirksomhed (the Pharmacy Act), para. 11, stk. 1(7).

59 Commentary to para. 1(1) of Lov 2009-02-10 nr. 100 om ændring af apotekerloven, sundhedsloven og lov for Grønland om forsyning, trafik, postbesørgelse m.v. (amendment of the Pharmacy Act and other acts).
} 
waste from the pharmacies and its destruction. For example, the Frederiksberg municipality on its website states that it provides pharmacies in its jurisdiction with collection equipment (specialised buckets) and afterwards arranges for the collection of the waste free of charge.$^{60}$ Pharmacies in this municipality are under the obligation to collect, sort and store household pharmaceutical waste in the provided equipment and order the collection of the waste and new collection equipment when needed. ${ }^{61}$

Household pharmaceutical waste is disposed of through incineration in temperatures above $1100^{\circ} \mathrm{C} .{ }^{62}$ The waste treatment plants receiving pharmaceutical waste must register 'the amount handled but not the specific type of waste. 63

While there is generally high trust in the system from the side of health professionals, private individuals lack the awareness of its existence. ${ }^{64}$ That is why the rate of return of household pharmaceutical waste is suspected to be low. ${ }^{65}$

One issue that we identify is the lack of information to the citizens on the use of the system, and, if information is available, it is sometimes inconsistent. For example, some organisations, municipalities and pharmacies recommend citizens to return the household pharmaceutical waste in its original packaging, ${ }^{66}$ others prescribe that it should be handed to the receiving pharmacist in a transparent plastic bag, ${ }^{67}$ and in other municipalities individuals can use special containers placed in pharmacies to drop-off their household

6o Commonly, municipalities have a special contract with certified waste handling companies to do so.

61 Frederiksberg Kommune, Affald fra apoteker, available online at https://www.frederiks berg.dk/affald-apotek (accessed 7 June 2021).

62 P.B. Poulsen, H.K. Standdorf, K. Hjuler and J.O. Rasmussen, Vurdering af malings miljøbelastning i anvendelsesfasen (2002), Miljøprojekt Nr. 662. Miljøministeriet.

63 J. Mehtonen, L. Äystö, V. Junttila, N. Perkola, T. Lehtinen, J. Bregendahl, Ü. Leisk, V. Kõrgmaa, P. Aarma, J. Schütz, M. Stapf, A. Kublina, I. Karkovska, M. Szumska, A. Bogusz, R. Kalinowski, S. Spjuth, K. Nyhlén, T. Jakobsson, S. Suzdalev and E. Kaskelainen, 'Good practices for take-back and disposal of unused pharmaceuticals in the Baltic Sea region, Clear Waters from Pharmaceuticals (CWPharma) Activity 4.1 Report', Reports of the Finnish Environment Institute 34 (2020), p. 14.

$64 \quad$ Ibid, p. 16.

65 NB the last quantitative investigation of the pharmaceutical take-back system in Denmark was carried out in 2009. See ibid, pp. 15-16.

66 Danmarks Apotekerforening, Virker for gammel medicin?, available online at https:// www.apoteket.dk/medicin/brug-af-medicin/anbefalinger/virker-gammel-medicin (accessed 23 June 2021).

67 Frederiksbergapotek, Medicinaffald, available online at https://frederiksbergapotek.dk/ medicinaffald/ (accessed 7 June 2021). 
pharmaceutical waste. ${ }^{68}$ While these differences may be logical locally, taking into account the resources of individual pharmacies, they may also confuse citizens and, thus, discourage the use of the take-back system.

\subsubsection{Greece}

Facing the situation of a breach of EU law due to not implementing Directive 2004/27/EC, Greece has established a temporary pharmaceutical take-back system by Ministerial Decision in 2012. ${ }^{69}$ According to Article 1 of this Decision, household pharmaceutical waste is to be collected and temporarily stored in special containers placed in rationally selected spaces (that are visible and easily accessible to citizens) in all pharmacies of the country. The containers are to be provided free of charge to the pharmacies by the Institute of Pharmaceutical Research and Technology SA (IFET). ${ }^{70}$ From the pharmacies, pharmaceutical waste is to be transported via the existing distribution networks to IFET's specially designed unit, located at Magoula close to Athens. ${ }^{71}$ The responsibility for the final disposal of the household pharmaceutical waste lies with IFET, that also bears the ultimate responsibility for the implementation of the Ministerial Decision under the supervision of the National Organization for Medicines. ${ }^{72}$ Interestingly, Article 7 of the Ministerial Decision also introduces the obligation of the involved public bodies to inform and train the public to use the collection system and not to dispose of pharmaceutical waste as a common household waste. Finally, Article 9 stipulates the possibility to impose administrative sanctions on non-compliant pharmacies. It is important to note that there is no incineration plant accepting household pharmaceutical

68 Frederiksberg Kommune, Apoteker - Vejledning I brug af indsamlingsmateriel (April 2020), available online at https://www.epaper.dk/frederiksberg/virk-fakta/apoteker -vejledning/ (accessed 7 June 2021).

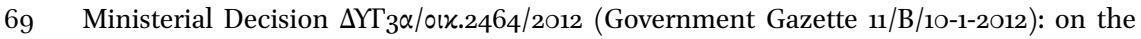
creation of a system for the collection, transport, temporary storage, management and destruction of household medicines and household medicine residues (NB a ministerial decision is a binding legal source in Greece); the legal basis of this specific decision is Article 43 of Law 4025/2011.

70 IFET is a public company and a subsidiary of the Greek National Organization for Medicines. According to the company's charter, one of its main objectives/purposes is the organisation, development and implementation of a safe system for collection, transport, temporary storage and management of household pharmaceutical waste.

71 Ministerial Decision $\Delta \mathrm{Y}_{3} \alpha / 0 \mathrm{o} \times .2464 / 2012$, Article 2.

72 Ministerial Decision $\Delta \mathrm{Y}_{3} \alpha / 0 \varkappa^{2} 2464 / 2012$, Article 5 and 6. 
waste in Greece as of now, meaning that the waste needs to be transported abroad for final disposal. ${ }^{73}$

The system had worked for some time, although not optimally, as not all pharmacies received the containers from IFET, and the public was not properly informed. ${ }^{74}$ Finally, the operation of this system fully collapsed in 2016, when IFET announced that their storage facility in Magoula was full and through a letter sent to pharmacies urged them to stop collecting household pharmaceutical waste..$^{75}$ In 2016, IFET opened a tender to find a new collector of household pharmaceutical waste from pharmacies, but due to the low requested price, nobody bid in the tender. ${ }^{76}$

It is difficult to find any official information about the existence and functioning of the take-back system in Greece. However, it appears that the system continues to function (and still is temporarily) under the auspices of IFET. ${ }^{77}$ According to a technical report prepared by IFET in 2019 , only about $45 \%$ of the unused and/or expired household pharmaceutical waste is being returned to the pharmacies. ${ }^{78}$ The ambition for the future is to create a new system that would fully implement EU legislation and still be co-managed by IFET. ${ }^{79}$

\subsubsection{The UK}

As in the other countries in our study, UK household pharmaceutical waste should be returned to pharmacies. Community pharmacies have the obligation to 'accept and dispose of unwanted drugs. ${ }^{80}$ From the studied jurisdictions, the UK has the largest number of legal acts regulating the functioning of

73 The only incineration plant dealing with medicinal waste in Ano Liossia disposes only of infectious and toxic medicinal waste, see ELLAKTOR Group, available online at https:// ellaktor.com/en/activity/diacheirisi-epikindynon-apovliton-ygeionomikon-monadon -ilektor/ (accessed 7 June 2021).

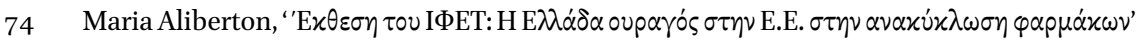
(IFET report: Greece at the tail in the EU in drug recycling), 10 July 2019, https://virus.com .gr/ekthesi-toy-ifet-i-ellada-oyragos-stin-e-e-stin-anakyklosi-farmakon/, retrieved 7 June 2021.

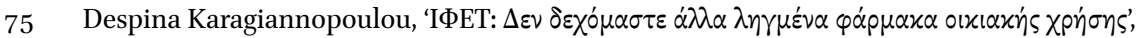
16 February 2016, https://www.iatronet.gr/eidiseis-nea/perithalpsi-asfalisi/news/34807/ ifet-den-dexomaste-alla-ligmena-farmaka-oikiakis-xrisis.html, retrieved 7 June 2021.

$76 \quad$ Ibid.

77 Aliberton, supra note 74.

$78 \quad$ Ibid.

79 Ibid.

8o The National Health Service (Pharmaceutical and Local Pharmaceutical Services) Regulations 2013, no. 349, Schedule 4, para. 13 (Regulations 2013). 
the pharmaceutical take-back system. ${ }^{81}$ According to Schedule 4, paras. 14(3) and 15 of Regulation 2013 pharmacies are obliged to:

1. sort the received pharmaceutical waste into solids (including ampoules and vials), liquids and aerosols;

2. store the drugs in containers provided by/on behalf of the NHSCB;

3. comply with any other statutory requirements in respect of storing or disposing of drugs of that description (such as the Hazardous Waste Regulations);

4. cooperate with any suitable arrangements that the NHSCB has in place for regular collection of the drugs from pharmacies' premises;

5. ensure that pharmacy staff is aware of the risks associated with the handling of pharmaceutical waste and the relevant procedures.

Moreover, according to the Waste duty of care $\mathrm{CoP},{ }^{82}$ pharmacies have further obligations in respect to handling, storing and transporting pharmaceutical waste. For example, it is stated that they must '[limit] access to the waste to only those that are authorised to handle it' (Waste duty of care CoP, Article 3.3), meaning among others that the pharmaceutical waste is stored safely and in a secure place away from areas of public access within the pharmacies' premises.

A regular collection of household pharmaceutical waste from pharmacies is to be arranged by NнSCв. If no such arrangements are made, pharmacies are not obliged to accept any medicines for disposal from households. ${ }^{83}$

Despite the detailed regulation of pharmaceutical take-back systems in the UK, a survey from 2013 shows that 'only $38 \%$ of the survey respondents in London were aware that they could return unused medicines to a pharmacy.' ${ }^{\prime} 4$ We find that $49 \%$ of the UK respondents in our study are aware of the pharmaceutical take-back system. ${ }^{85}$ This reveals that there is still plenty of room for improvement when it comes to raising awareness of the existence and functioning of the system.

81 Regulations 2013; Hazardous Waste Regulations (England and Wales) 2005, no. 894; The Controlled Waste (England and Wales) Regulations 2012, no. 811; The Carriage of Dangerous Goods and Use of Transportable Pressure Equipment Regulations 2009, no. 1348; Environmental Protection Act 199o, c. 43; Statutory guidance; Waste duty of care: code of practice, as updated on 26 November 2018 (Waste duty of care CoP); The Waste (England and Wales) Regulations 2011, no. 988; The List of Wastes (England) Regulations 2005, no. 895. NB separate laws related to Scotland or Northern Ireland are not included in this overview.

$82 \quad$ Supra note 81.

83 Regulations 2013, Schedule 4, para. 14(2).

84 Amaral and Fop, supra note 38, p. 22.

85 See below, Section 4.1. 


\section{Call for Streamlining of Pharmaceutical Take-Back Systems across the EU}

The insertion of the requirement to introduce an appropriate collection system for unused and/or expired medicinal products into the Community code initiated not only implementation actions, but also scientific interest into the design and functioning of the established take-back systems. Already early on, it has been pointed out that the implementation of and the compliance level with the requirement is very heterogeneous throughout the EU. ${ }^{86}$ Our overview of the four selected countries in Section 2.2 confirms this. The differences in the implementation of the prescribed pharmaceutical take-back systems and the lack of aligned information provided to the EU citizens have been identified as possible hindrances for effective functioning of the systems. ${ }^{87}$ Already in 2008, we saw the first calls for the harmonisation of the take-back systems across the EU. 88 This recommendation has been quickly lifted also by the European Environmental Agency ${ }^{89}$ and reiterated in the BIO Is study. ${ }^{90}$ Under the title 'Developing and harmonising the implementation of collection systems for unused medicinal products', the BIO Is study called for '[providing] streamlined information to patients regarding the importance and current efficiency of the collection of unused medicines' (Action 5 ) $^{91}$ and for '[d] eveloping and publishing European guidelines for the successful implementation of collection systems' (Action 8). ${ }^{92}$ Reading these suggestions for action carefully, we notice, though, that the study does not directly suggest that the pharmaceutical take-back systems should be fully unified across the EU, but rather that there should be a common guidance from the EU to the Member States

86 K. Kümmerer and M. Hempel (eds.), Green and Sustainable Pharmacy (Heidelberg: Springer, 2010); European Environment Agency (EEA), 'Pharmaceuticals in the environment Results of an EEA workshop' (2010), EEA Technical report No 1/2010, p. 26.

87 Deloitte (in partnership with Milieu Ltd, Ineris and Pr. Klaus Kümmerer), Deloitte Sustainability, Background document for public consultation on pharmaceuticals in the environment (September 2017), available online at https://ec.europa.eu/info/sites/ default/files/background_document_public_consultation_pharmaceuticals_environ ment.pdf (accessed 7 June 2021).

88 KNAPPE, final report, p. 20: "It is recommended that the drafting of an EU guideline on take-back schemes could be helpful to further establish this management strategy in European countries."

$89 \quad$ EEA, supra note 86, p. 5: "Based on the positive experiences at local levels, an EU-wide take back scheme via pharmacies should be established."; and p. 10: “[...] take back scheme rules for unused pharmaceuticals should be harmonised in the EU [...]'.

$90 \quad$ BIO Is, supra note 9 .

$91 \quad$ Ibid., p. 173.

92 Ibid., p. 173. 
on best practice, and that the information provided to the citizens should be aligned. This is mirrored in the latest EU policy on PiE from 2019, which states that the Commission will "[a]ssess the implementation of collection systems for unused pharmaceuticals and consider how their availability and functioning could be improved ... ${ }^{93}$ Therefore, it is not sure that the EU is convinced that the unification of the take-back systems is the best way to go forward, but it aims to evaluate it. Our article provides data to inform this assessment.

A non-profit organisation named Health Care Without Harm ${ }^{94}$ has repeatedly and aloud voiced the potential of harmonising pharmaceutical take-back systems across the EU. ${ }^{95}$ Moreover, the organisation calls for more data and reporting from the Member States, and for improved communication to the citizens, including the introduction of a clear message on the labelling. ${ }^{96}$ However, other voices remind us that 'one-size fits all' solutions do not always work and that we need to take geographical, cultural, and social factors into consideration before introducing new rules. ${ }^{97}$

Intrigued by this policy and academic discussion, we decided to complement the dogmatic research with original empirical data. The design and results of the empirical study of the four selected jurisdictions are presented in the section below.

\section{$4 \quad$ Empirical Study}

The diverse implementation of pharmaceutical take-back systems across the EU followed by the calls for their harmonisation and even unification led us to consider whether and eventually how should such harmonised/unified

93 Supra note 13, p. 10.

94 HCWH is a non-profit network of European hospitals and healthcare providers, healthcare systems, local authorities, research/academic institutions and environmental and health organisations. See https://noharm-europe.org/content/europe/who-we-are (accessed 7 June 2021).

95 HCWH Europe, HCWH Europe Recommendations on pharmaceuticals in the environment - September 2016, available online at https://noharm-europe.org/sites/ default/files/documents-files/4304/2016-o9-. 27\%2oHCWH\%2oEurope\%2oPharmaceuti cals\%2oin\%2othe\%2oenvironment\%2oposition\%2opaper.pdf (accessed 7 June 2021), part 9 .

$96 \quad$ Ibid.; Amaral and Fop, supra note 38.

97 F.Thomasand theWorld Health Organization(RegionalOffice forEurope),'Pharmaceutical waste in the environment: a cultural perspective', Public Health Panorama 3(o1) (2017) 127-132, available online at https://apps.who.int/iris/handle/10665/254734 (accessed 7 June 2021). 
systems be designed to maximise their effectiveness. As a part of a larger study, ${ }^{98}$ we thus conducted a cross-cultural, online trial in four selected countries: Denmark, Greece, Czechia and the UK. The aim of the first part was to collect data about the participants' past behaviour, awareness, preferences and beliefs of the PiE problem in general and the take-back systems in particular via a survey. The results of the survey are analysed and discussed below. The ultimate objective was to explore, whether regulatory harmonisation is possible and desirable based on the information from the countries in relation to the PiE problem and pharma take-back systems.

The other part consisted of an experimental study of the effect of the design of information on pharmaceutical take-back systems by using a combination of personalised risk and loss-aversion information on the participants' intention to use the systems in the future. A detailed description of the protocol of the experimental study and analyses of the results appear elsewhere. ${ }^{99}$

The empirical study was conducted online in the summer of 2020 . Altogether, 1330 participants, all legally competent adults, were recruited by Qualtrics Online Panels, following a quota sampling based on age and gender in each country. This satisfied our sample size goal of 300 participants per country. After conducting an online experiment, the participants were asked to report the frequency in the use of medications, previous experience with disposal of unused/expired medications, awareness of take-back systems in the respective country, knowledge about antimicrobial resistance, preferences about disposal of unused/expired medications, and their perception of the improper disposal of unused and/or expired medications as either an environmental or a health problem.

\subsection{Results}

Considerable differences among the countries are observed in respect to the public awareness of the existence of pharmaceutical take-back systems and their actual use (Table 1). While $83 \%$ of the Czech respondents report that they are aware of the pharmaceutical take-back systems, this number reaches $64 \%$ in Denmark, and lies around $50 \%$ in Greece and in the UK. The percentage of awareness is somehow mirrored in the use of the systems; to the question 'How do you mainly deal with your unused and/or expired medicines?', $63 \%$ Czech, $54 \%$ Danish, $46 \%$ Greek and $40 \%$ UK respondents reply that they 'return them

\footnotetext{
98 The full results of the larger study are reported in P. Mitkidis, P. Chrysochou, V. Obolevich and K. Mitkidis, 'Effectiveness of environmental health and loss framing on household pharmaceutical take-back schemes: three pre-registered, randomised, controlled, crosscultural trials', Working Paper (2021).

Ibid.
} 
TABLE 1 Past behaviour, perceptions, and beliefs regarding pharmaceutical take-back schemes

\begin{tabular}{llllllll}
\hline $\begin{array}{l}\text { Total } \\
(N=1330)\end{array}$ & $\begin{array}{l}\mathrm{CZ} \\
(N=331)\end{array}$ & $\begin{array}{l}\mathrm{DK} \\
(N=335)\end{array}$ & $\begin{array}{l}\text { GR } \\
(N=322)\end{array}$ & $\begin{array}{l}\mathrm{UK} \\
(N=342)\end{array}$ \\
$N$ & $\%$ & $N$ & $\%$ & $N$ & $\%$ & $N$ & $\%$
\end{tabular}

How do you mainly deal with your unused and/or expired medicines?

\begin{tabular}{|c|c|c|c|c|c|c|c|c|c|c|}
\hline $\begin{array}{l}\text { I flush them down } \\
\text { the drain (toilet or } \\
\text { sink) or throw them } \\
\text { into the garbage bin }\end{array}$ & 234 & 17.6 & 22 & 6.6 & 53 & 15.8 & 97 & $3^{0.1}$ & 62 & 18.1 \\
\hline $\begin{array}{l}\text { I return them to the } \\
\text { pharmacy/doctor } \\
\text { or other collection } \\
\text { place }\end{array}$ & 673 & $5^{\circ} .6$ & 208 & 62.8 & 182 & 54.3 & 148 & 46.0 & 135 & 39.5 \\
\hline $\begin{array}{l}\text { I keep any unused } \\
\text { medicines at home/ } \\
\text { I do not check for } \\
\text { expired medicines }\end{array}$ & 423 & 31.8 & 101 & 30.5 & 100 & 29.9 & 77 & 23.9 & 145 & 42.4 \\
\hline
\end{tabular}

Are you aware of the pharmaceutical take-back schemes (i.e., possibilities to return them to pharmacies or collection points) in your country?

$\begin{array}{lllllllllll}\text { Yes } & 830 & 62.4 & 275 & 83.1 & 215 & 64.2 & 171 & 53.1 & 169 & 49.4\end{array}$

How many of your expired and/or unused medicines do you return to your local pharmacy/ other collection place?*

$\begin{array}{lrrrrrrrrrr}\text { None } & 160 & 12.0 & 65 & 19.6 & 33 & 9.9 & 20 & 6.2 & 42 & 12.3 \\ \text { Some } & 276 & 20.8 & 111 & 33.5 & 57 & 17.0 & 50 & 15.5 & 58 & 17.0 \\ \text { Most of all } & 394 & 29.6 & 99 & 29.9 & 125 & 37.3 & 101 & 31.4 & 69 & 20.2\end{array}$

Improper disposal of unused and/or expired medicines (such as flushing pharmaceuticals down the toilet or sink or throwing them into the rubbish bin)

$\begin{array}{lllllllllll}\text { is an environmental } & 1,036 & 77.9 & 255 & 77.0 & 263 & 78.5 & 25^{1} & 78.0 & 267 & 78.1\end{array}$ problem

$\begin{array}{lllllllllll}\text { is a health problem } & 294 & 22.1 & 76 & 23.0 & 72 & 21.5 & 71 & 22.0 & 75 & 21.9\end{array}$

What does antimicrobial resistance mean (AMR)?

$\begin{array}{lllllllllll}\text { Antibiotics stop } & 721 & 54.2 & 165 & 49.8 & 181 & 54.0 & 191 & 59.3 & 184 & 53.8 \\ \text { working in treating } \\ \text { infections }\end{array}$




\begin{tabular}{|c|c|c|c|c|c|c|c|c|c|c|}
\hline & \multicolumn{2}{|c|}{$\begin{array}{l}\text { Total } \\
\left(N=133^{\circ}\right)\end{array}$} & \multicolumn{2}{|c|}{$\begin{array}{l}\mathrm{CZ} \\
(N=\mathbf{3 3 1})\end{array}$} & \multicolumn{2}{|c|}{$\begin{array}{l}\text { DK } \\
(N=335)\end{array}$} & \multicolumn{2}{|c|}{$\begin{array}{l}\text { GR } \\
\left(N=\mathbf{3}^{22}\right)\end{array}$} & \multicolumn{2}{|c|}{$\begin{array}{l}\text { UK } \\
(N=342)\end{array}$} \\
\hline & $N$ & $\%$ & $N$ & $\%$ & $N$ & $\%$ & $N$ & $\%$ & $N$ & $\%$ \\
\hline $\begin{array}{l}\text { High risk of exposure } \\
\text { to diseases (people } \\
\text { become more vulner- } \\
\text { able to develop new } \\
\text { illnesses) }\end{array}$ & 134 & 10.1 & 22 & 6.6 & 25 & $7 \cdot 5$ & 49 & 15.2 & 38 & 11.1 \\
\hline $\begin{array}{l}\text { Lowered biodiversity } \\
\text { (some species of } \\
\text { plants and/or ani- } \\
\text { mals will extinct) }\end{array}$ & 80 & 6.0 & 27 & 8.2 & 20 & 6.0 & 11 & $3 \cdot 4$ & 22 & 6.4 \\
\hline I do not know & 395 & 29.7 & 117 & $35 \cdot 3$ & 109 & 32.5 & 71 & 22.0 & 98 & 28.7 \\
\hline
\end{tabular}

How would you prefer THE MOST to return unused and/or expired medicines?

\begin{tabular}{|c|c|c|c|c|c|c|c|c|c|c|}
\hline $\begin{array}{l}\text { I prefer to hand } \\
\text { them over }\end{array}$ & 475 & $35 \cdot 7$ & 55 & 16.6 & 161 & 48.1 & 98 & 30.4 & 161 & $47 \cdot 1$ \\
\hline $\begin{array}{l}\text { I prefer to return } \\
\text { them in a non- } \\
\text { transparent bag }\end{array}$ & 125 & 9.4 & 22 & 6.6 & 28 & 8.4 & 37 & 11.5 & 38 & 11.1 \\
\hline $\begin{array}{l}\text { I prefer to leave } \\
\text { them in an unused } \\
\text { and/or expired medi } \\
\text { cines collection box }\end{array}$ & 730 & 54.9 & 254 & 76.7 & 146 & 43.6 & 187 & $5^{8.1}$ & 143 & 41.8 \\
\hline
\end{tabular}

Where would you prefer THE MOST to return your expired and/or unused medicines?

\begin{tabular}{lrrrrrrrrrr} 
To a pharmacy & 840 & 63.2 & 188 & 56.8 & 203 & 60.6 & 219 & 68.0 & 230 & 67.3 \\
To your doctor & 35 & 2.6 & 6 & 1.8 & 9 & 2.7 & 6 & 1.9 & 14 & 4.1 \\
To a 'convenient & 321 & 24.1 & 87 & 26.3 & 72 & 21.5 & 88 & 27.3 & 74 & 21.6 \\
place', such as a & & & & & & & & & & \\
$\begin{array}{l}\text { supermarket or a } \\
\text { petrol station }\end{array}$ & & & & & & & & & & \\
$\begin{array}{l}\text { I do not care } \\
\text { d }\end{array}$ & 134 & 10.1 & 50 & 15.1 & 51 & 15.2 & 9 & 2.8 & 24 & 7.0 \\
\hline
\end{tabular}

\footnotetext{
* Answered only from those being aware.
} 
to the pharmacy/doctor or other collection place'. This shows not only that with raising awareness, the use of pharmaceutical take-back systems raises, but also that there is a gap in motivating those people who know about the systems' existence to actually use them. This gap is largest in Czechia, where $20 \%$ of the people who are aware of the take-back systems' existence, do not return their unused and/or expired medicines at the collection point.

The levels of improper disposal of household pharmaceutical waste also differ considerably among the countries studied, and to some extent negatively relate to the low levels of awareness of the pharmaceutical take-back systems. Surprisingly, only $7 \%$ of the Czech respondents answer that they mainly deal with household pharmaceutical waste by flushing it down the drain (through the toilet or sink) or throwing it into the garbage bin. ${ }^{100}$ This number climbs up to $30 \%$ in Greece, suggesting that awareness of take-back systems might be associated not only with their use, but also with lowering of the amounts of irresponsibly disposed household pharmaceutical waste. Now, as our data show that there is no direct relationship between the awareness of take-back systems and the ways of disposal, a question arises what happens with unused/ expired medicines, which are neither returned to a pharmacy nor disposed of through the sewage system or garbage bin. These medicines are most commonly stockpiled at home for later use or simply because their expiration date is not checked. Again, we observe a difference among the countries, ${ }^{101}$ but this difference cannot be easily explained by the rest of the data. We hypothesise that the stockpiling of medicines at home depends on a combination of policy and cultural factors (such as prescription regulation and practice, price of medicines, or the level of self-medication).

The discussion of the PiE problem is often voiced in the context of antimicrobial resistance. ${ }^{102}$ Yet, from our data, the understanding of AMR does not seem to be linked to the awareness of the pharmaceutical take-back systems. When respondents were asked what AMR means, only a little under $50 \%$ of the Czech respondents answered correctly, while almost $6 \circ \%$ of the Greek respondents gave a correct answer. That could indicate that making the connection between AMR and pharmaceutical take-back systems in the communication

\footnotetext{
100 This number differs from the $25 \%$ reported by SUKL. This difference can be explained by the fact that SUKL's number is based on estimations only and/or by social desirability bias in surveys, see I. Krumpal, 'Determinants of social desirability bias in sensitive surveys: a literature review', Quality \& Quantity 47(4) (2013) 2025-2047.

$101 \mathrm{CZ} 31 \%$; DK 30\%; GR 24\%; UK 42\%.

102 K. Kümmerer, 'Pharmaceuticals in the Environment', Annual Review of Environment and Resources 35(1) (2010) 57-75, DOI: 10.1146/annurev-environ-o528o9-161223.
} 
to the public could bear a potential of increasing the use of the system in some jurisdictions and raising awareness of AMR in others.

Finally, we asked our respondents about their preferences in regard to two features of pharmaceutical take-back systems: where and how the return takes place. Unsurprisingly, most respondents $(63 \%)$ chose a pharmacy as a preferred place of returning unused/expired medication. This can be explained by the fact that pharmacies are nowadays the points of return in all four countries studied. Humans do not easily change their habits, ${ }^{103}$ so those who use pharmaceutical take-back systems would most probably prefer that the location remains the same. Interestingly, about one fourth of the respondents noted that they would prefer to return unused/expired medicines 'to a "convenient place", such as a supermarket or a petrol station'. This is most probably relevant to those, who do not have easy access to a local pharmacy. ${ }^{104}$

While the responses about the preferred location did not differ significantly among the four countries, we see larger disparities in preferred manner of return. We gave the respondents three options to choose from: handing the medication over; handing them over in a non-transparent bag; and leaving it in a collection box. Overall, $55 \%$ of all respondents chose the collection box as the preferred manner, followed by $36 \%$ favouring simple hand-over of the pharmaceutical waste, and $9 \%$ hand-over in a non-transparent bag. Yet, the numbers differ significantly with $77 \%$ Czech respondents in contrast to only $42 \%$ UK respondents preferring the collection box, and $48 \%$ Danish respondents in contrast to $17 \%$ Czech respondents preferring a simple hand-over. It should be noted, that nowadays a simple hand-over is the only way to return unused/expired medications to pharmacies in Czechia, so here the numbers are especially interesting. The reported preferences can possibly be explained by a mix of local conditions (such as the waiting time in pharmacies or the level of privacy at the counter) and cultural and social aspects (such as the level of trust in the society or the desire to stay anonymous).

103 B. Verplanken, 'Beyond frequency: Habit as mental construct', British Journal of Social Psychology 45(3) (2006) 639-656, DoI:10.1348/014466605X49122; B. Verplanken and S. Orbell, 'Reflections on past behavior: a self-report index of habit strength', Journal of Applied Social Psychology 33(6) (2003) 1313-1330, DoI:10.1111/j.1559-1816.2003.tbo1951.x; W. Samuelson and R. Zeckhauser, 'Status quo bias in decision making' Journal of Risk and Uncertainty 1(1) (1988) 7-59, DOI:10.1007/BFooo55564.

104 Inconvenience (lack of disposal locations, distance to disposal locations or lack of time) was analysed in semi-structured interviews which were conducted in the city centres of the capital cities of six European countries: Belgium, Hungary, Italy, Lithuania, Portugal and the United Kingdom, see Amaral and Fop, supra note 38. 
Finally, the results of the experimental part of the empirical study (which are not the main focus here) suggest that the environmental negative framing works best. ${ }^{105}$ This reflects the framing of the information on PiE that the public has been exposed to so far. As the science on the exact impact (and its scale) of PiE on human health is inconclusive, public authorities have so far based any legislative action, awareness raising campaigns and distributed popular information on the PiE on the known and proven negative impacts to the environment. ${ }^{106}$ This exposure seemed to have formed the perception of the problem, as $80 \%$ of our respondents report to perceive the PiE as an environmental problem rather than a health problem. This number is consistent in all four countries.

\section{Discussion}

Through the study of the legislation regulating pharmaceutical take-back systems in the four countries, we confirm that eventhough EU Member States have implemented Article 127 b of the Community code, they have done it differently. The empirical study confirmed the existence of varied levels of use of the systems as well as differences in individuals' beliefs and behaviour. It also provided input about which framing of the PiE problem induces the highest levels of intention to use the systems in the future.

Based on our theoretical and empirical research, we will discuss the following questions: should the pharmaceutical systems be harmonised or even unified across the EU to mitigate the PiE problem? And if so, how should such harmonised/unified take-back systems be designed? Finally, what would be the appropriate regulatory approach by the EU if harmonisation/unification is desirable?

\subsection{Should the Pharmaceutical Take-Back Systems Be Harmonised/ Unified across the EU to Mitigate the PiE Problem?}

The EU has legislated on the requirement for an 'appropriate collection system' of unused/expired pharmaceuticals in 2004. Without further guidelines on how such systems should be designed or how the collected pharmaceutical

105 This result is only statistically significant for the pooled sample. For details, see P. Mitkidis et al., supra note 98 .

106 HCWH, Pharma in the environment, available online at https://pharmaenvironment.org (accessed 11 May 2021); Umwelt Bundesamt, Arzneimittel und Umwelt (17 October 2019), available online at https://www.umweltbundesamt.de/themen/chemikalien/arzneimit tel/humanarzneimittel/arzneimittel-umwelt (accessed 11 May 2021). 
waste should be disposed of after its collection, the Member States have implemented the requirement in a widely different manner. These national differences were explained by differences in local conditions as well as cultural, economic and social differences. ${ }^{107}$ However, due to the lack of more streamlined EU guidelines on pharmaceutical take-back systems, exchange of experience and best practice among Member States, and streamlined communication towards the European citizens, the effectiveness of the pharmaceutical take-back systems remains limited. According to our data, EU citizens in the four selected Member States disposed of only about $50 \%$ of their household pharmaceutical waste through the assigned take-back systems. That is the same number as in $2013 .{ }^{108}$ This shows that despite the increased interest in pharmaceutical take-back systems in the public discourse of the PiE issues, ${ }^{109}$ their effectiveness stagnates. Providing streamlined guidelines centrally by the EU institutions or legislation based on best practice as assembled from national experience accompanied by a harmonised and optimally framed communication to EU citizens has the potential to increase the effectiveness of pharmaceutical take-back systems.

\subsection{How Should a Harmonised/Unified Take-Back System Be Designed?}

Regulatory interference is most effective (enjoys the highest level of compliance) when it corresponds to the preferences and moral norms of the regulated subjects. ${ }^{110}$

As for the practical setting of pharmaceutical take-back systems, we see a clear preference of the respondents to return their household pharmaceutical waste to pharmacies. This, as hypothesised earlier, can be explained by the current practice. Another reason for this can be that people naturally associate pharmacies with medicines and thus feel most comfortable with disposal of their pharmaceutical waste there.

The disparities in the preferred manner of return (handing over vs. dropping them in a collection box) may be hard to overcome. Cultural and social norms, such as trust or individualism, come into play here. ${ }^{111}$ However, if the

\footnotetext{
107 Amaral and Fop, supra note 38, p. 2.

108 BIO Is, supra note 9.

109 B. Roig and E. Touraud, 'Trier ses médicaments pour préserver l'environnement', Cyclamed, available online at https:/www.cyclamed.org/pourquoi-trier/environnement/ (accessed 10 May 2021).

110 J. Habermas, Between Facts and Norms: Contributions to a Discourse Theory of Law and Democracy (Malden: Polity Press, 1996).

111 E.g., G. Hofstede, G.J. Hofstede and M. Minkov, Cultures and Organizations: Software of the Mind. Third Edition (New York, NY: McGraw-Hill, 2010); S.H. Schwartz, 'A theory of
} 
EU decides to unify the pharmaceutical take-back systems, using collection boxes instead of simple hand-over should be considered, since our results show that it is overall, across the four countries together, the most preferred choice $(55 \%)$, compared to handing over $(36 \%)$. Collection boxes might also increase the feeling of convenience, as there is no need to wait in the line to the counter, support anonymity for those who fear to be judged in connection with handing over unused medication, and decrease the time (and possibly cost) of pharmacies invested in pharmaceutical waste handling. Based on the results of our study we would thus recommend using collection boxes placed in pharmacies as the preferred design of pharmaceutical take-back systems in the EU.

\subsection{What Would Be the Appropriate Regulatory Approach by the EU If the Harmonisation/Unification Is Desirable?}

The pharmaceutical take-back systems are so far vaguely regulated for in EU pharmaceutical law, the provision lying on the borderline between waste and health law areas. As argued above, the protection of human health is stipulated for with a stronger imperative than environmental protection in EU primary law. However, this is not observed in the regulation of pharmaceutical takeback systems and the information provided about them by authorities to the public. Why is the focus given to the environmental rather than health aspects of pharmaceutical waste?

The first reason for this is the already discussed lack of scientific certainty about the scale of detrimental effects of pharmaceutical waste on human health. However, such uncertainty could potentially be overcome by the application of the precautionary principle, if political will exists. ${ }^{112}$ Another reason is the question of competence. Environmental protection is an area of shared competence between the EU and its Member States, ${ }^{113}$ but in the public health area the EU has only complementary competence. ${ }^{114}$ Yet, these two areas are inherently connected - a healthy environment is a precondition for good human health, ${ }^{115}$ and environmental protection is among the three main

cultural values and some implications for work', Applied Psychology 48(1) (1999) 23-47, DOI:10.1111/j.1464-0597.1999.tbooo47.x.

112 European Commission, 'Communication from the European Commission on the precautionary principle', 2000, СОм (2000) 1, Brussels.

113 Article 4(2) TFEU.

114 Article 6 TFEU.

115 Article 191(1); EU, 'Chemicals Strategy for Sustainability Towards a Toxic-Free Environment', Brussels, 14 October 2020, СОM(2020) 667 final. 
objectives of the EU health policy. ${ }^{116}$ This interconnectedness is increasingly recognised and untangled by the EU and its Member States, allowing the EU to enter the regulatory space, which has so far been predominantly reserved for national regulatory competence.

With the blurring of boundaries between the policy areas, the EU could regulate for harmonisation of pharmaceutical take-back systems. Yet, it is hard to imagine that this could be successfully done through amendments of the Community code, as the main aim here is to establish a common market for human medicines. However, as the tobacco regulation ${ }^{117}$ example shows, in recent years the EU and the Court of Justice of the European Union (CJEU) are diligently trying to balance the protection of human health and internal market measures by paying equal attention to both of them: pursuing the facilitation of the internal market while at the same time ensuring a high level of protection of human health. ${ }^{118}$ Bearing in mind the principle of conferral, ${ }^{119}$ the EU action aimed at public health shall merely complement national policies $^{120}$ and leave the fundamental choices to the Member States. However, Member States need to deal with an active role of the EU in public health questions, because the EU is responsible for providing a high level of health protection in its legal, regulatory and administrative measures, and assist Member States in their action on health. Moreover, EU law enjoys "supremacy" over conflicting national law, requiring national courts to "set aside" any contradictory national law and apply EU law in its place. ${ }^{121}$

A special legal act based on Article 114 TFEU could potentially be adopted. However, based on the case law of the CJEU, in order to rely on the harmonisation power of Article $114 \mathrm{TFEU}$, there should be divergences between existing national laws that create or are capable of creating obstacles to trade. These constraints should "obstruct the fundamental freedoms" and "directly affect the functioning of the internal market" or "significantly distort competition".122

116 European Parliament, Public Health (factsheet) (March 2021), available online at https:// www.europarl.europa.eu/factsheets/en/sheet/49/public-health (accessed 7 June 2021).

117 Directive 2014/40/EU of the European Parliament and of the Council of 3 April 2014 on the approximation of the laws, regulations and administrative provisions of the Member States concerning the manufacture, presentation and sale of tobacco and related products and repealing Directive 2001/37/EC [2014] OJ L127/1.

118 Case C-547/14, Philip Morris Brands SARL [2016], ECLI:EU:C:2016:325 (Philip Morris), para. 60.

119 Treaty on European Union (TEU), Article 5(2).

120 TFEU, Article 168(1).

121 Case 6/64, Flaminio Costa v E.N.E.L. [1964], ECR 585, ECLI:EU:C:1964:66.

122 Case C-376/98, Germany v Parliament and Council [2000], ECR I-08419, ECLI:EU:C:2000:544, para. 84; Case C-434/o2, Arnold André [2004], ECR I-11825, 
Considering the nature of the regulatory differences of the pharmaceutical take-back systems among Member States, it might be difficult to establish that they create or are capable of creating obstacles to trade in the future.

Built on the environmental protection legal basis, the Waste Framework Directive could be another place for a pharmaceutical take-back systems regulation. ${ }^{123}$ Preamble 17 of the Waste Framework Directive mentions pharmaceutical take-back systems, particularly, that waste collection schemes for medicines from household due to low risk and separate collection should not be subject to registration. However, using the Directive to regulate pharmaceutical waste management for the ultimate goal of environmental protection could amount to overstepping the competence provisions in the TFEU. ${ }^{124}$ The principle of subsidiarity and the principle of proportionality should not be neglected, allowing measures only if they do not exceed what is necessary to achieve the goal.

Considering the above, a better solution would probably be either to use a non-binding legal act of recommendation or Commission's guidelines, or to adopt a special legal act within the waste law area, where the EU has the competence to regulate.

\section{Conclusion}

Effective pharmaceutical take-back systems are one of the easier achievable pieces in the EU's regulatory solutions to the PiE puzzle. However, as reported by others and confirmed in this paper, the current setting of the take-back systems in the EU is not optimal, reaching a compliance level of only about $50 \%$ by citizens. Thus, improvements are necessary. The EU is currently assessing the functioning of pharmaceutical take-back systems and the potential for their improvements, including the question of whether harmonisation of the system across the EU is desirable. Our paper provides both dogmatic analyses and empirical data, which contribute to such an assessment.

We find that there are considerable differences both in regulation and design of pharmaceutical take-back schemes across the studied jurisdictions.

ECLI:EU:C:2004:80o, para. 30; Case C-38o/o3, Germany v Parliament and Council [2006], ECR I-11573, ECLI:EU:C:2006:772, para. 37; Case C-210/o3, Swedish Match [2004], ECR I-11893, ECLI:EU:C:2004:802, para. 29; Case C-58/o8, Vodafone and Others [2010], ECR I-4999, ECLI:EU:C:2010:321 para. 32; Philip Morris, para. 58.

123 Directive 2008/98/EC of the European Parliament and of the Council of 19 November 2008 on waste and repealing certain Directives [2008] oJ L 312/3.

124 Similarly as in the original tobacco directive. 
We also find that there is a potential for raising the effectiveness of pharmaceutical take-back systems through their harmonisation at the EU level, and that the EU has the competence and available tools to regulate in this area.

Our findings also lead to the discussion of whether the current framing of $\mathrm{PiE}$ as an environmental issue by the public authorities is contributing or hindering the enjoyment of the full benefits of pharmaceutical take-back systems. We thus call for more research into this area, specifically into the process and impacts of reframing such a defined issue - could we increase the use of pharmaceutical take-back systems, or would we lose already established compliance? We note that the legal framework of EU law does not hinder such a reframing, providing the EU possibilities through the integration principle of human health and environmental protection as well as the possibility to reach for the precautionary principle in the regulatory toolbox.

\section{Acknowledgements}

The authors thank Adriana Šefč́iková and Vaia Itsiou, both research assistants at the Department of Law, Aarhus University, for excellent research assistance during the writing of this article. The research was conducted within the project "Regulating emerging pollutants: designing law amidst constant scientific knowledge development" funded by the Carlsberg Foundation, grant no. CFig-017o. 